\title{
The Study on the Application Mode of Plant Therapy in Landscape Architecture Construction
}

\author{
Xin LIU \\ Kunming University
}

Keywords: Botanical garden; landscape architecture construction; Environment

\begin{abstract}
Botanical garden is the application mode of plant therapy in landscape architecture, and the implementation of high quality plant therapy is the basis of plant therapy. Well-designed botanical garden stimulates a variety of sensory organs and causes deeper feelings. Analysis of the implementation of plant therapy at home and abroad, summed up the botanical garden design goals and guidelines. Compared with the conventional design, the botanical garden is designed to pay more attention to the needs of human beings and pursue the harmony and unity between man and nature. For different people and different places, puts forward the design points of plant garden therapy, the differences in the design, to meet the different needs of users, reflect the harmony on the design of people-oriented, ecological nature, and environment.
\end{abstract}

\section{Introduction}

China will promote ecological civilization construction of ecological civilization and the Peking University [1-2]. Research Center released the "ecological city residents demand investigation report" pointed out: the city residents to improve the ecological environment of the desire and the demand is very urgent, it needs all-round trend. The ideal living environment for urban residents is the clean air; the street and the district; the tree lined; the green space; the abundant and clean water. The most natural environment for city dwellers to be close to is the grass, trees and forests [3-4]. Forest Park and suburban rural areas are the most popular places for holidays and leisure. The report also pointed out that the current urban ecological environment construction, one-sided pursuit of uniform, ornamental effect, blindly pursue urban landscaping, lighting, is a misunderstanding of urban ecological environment construction and misunderstanding, which is as Figure.1.

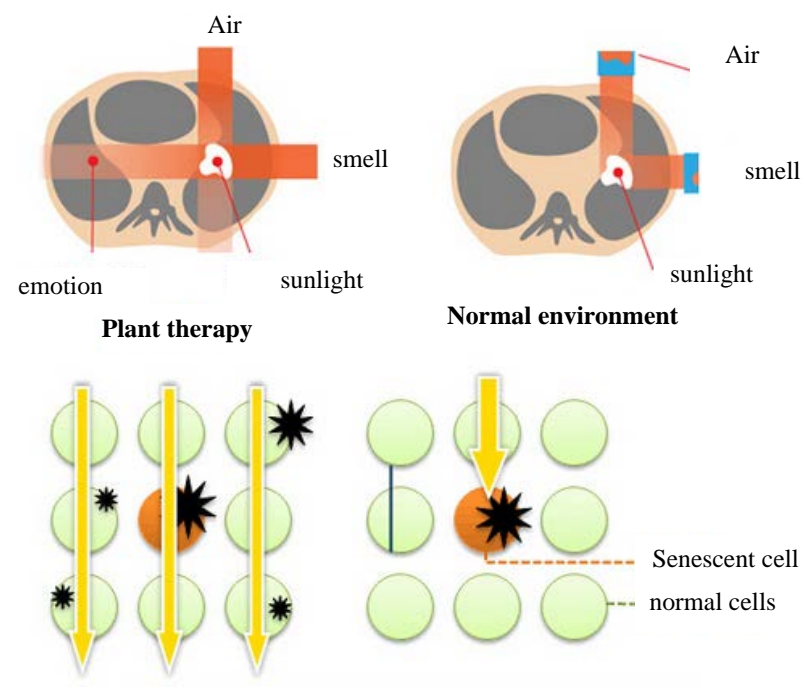

Fig.1. The Efficacy of plant therapy

At present, the overall satisfaction of urban ecological environment quality needs further improvement, which requires the concerted efforts of governments at all levels and the whole society. 


\section{State of the Art}

Japan carefully investigated the development of horticultural therapy in Europe and America, and published the investigation report on horticultural therapy. The twenty-fourth International Horticultural Society was held in Japan. An academic conference on exchange of horticultural therapy and research was held after the meeting. The horticultural therapy seminar was established in Japan, and the Horticultural Therapy Research Association of Japan was established in the fall. The survey conducted by the Japan greening Center showed that more than $60 \%$ of the disabled nursing homes in the country began horticultural therapy. horticultural therapy activities were carried out in various parts of Japan. Henson in horticultural therapy more than 20 years' experience in "Horticulture as Therapy", a book on the case as the core, the practical experience and theoretical treatment together, this is the operational guidelines of horticultural therapy. Japan has also vigorously developed horticultural therapy, landscape treatment facilities have been set up all over the country, and landscape therapy has developed rapidly over the past few years. The teaching and research of horticultural therapy are also unfolding rapidly. The combination of geographical conditions, Japan vigorously implements the forest therapy, and achieved good results.

\section{The Five Sense Stimulus of Plants to Human Beings}

Landscape architecture provides different sensory stimuli, including sight, hearing, taste, touch and smell. In particular, the shape and color of plants in the garden have a stimulating effect on vision, aroma, smell, edible plants, sense of taste, and the sense of sense of touch in the stems and leaves of plants. In addition, the nature of insects, birds, water and wind have a stimulating effect on the hearing. Sick in bed to the outdoors to bathe in the natural atmosphere, to receive sunlight, light and shade to give visual stimulation, feel the temperature of the skin stimulation, but also the landscape of the five sense of human stimulation [5-6]. The day of gardening activities, accept sunbathing, which go to bed at night after fatigue, to develop good habits and living habits, to maintain normal operation of the body clock, which has certain curative effect on patients with insomnia. Five senses are vision, hearing, smell, taste, touch". The results of modern psychological research show that more than eighty-five percent of the total perceived information comes from audio-visual senses. In general sense, the main function of landscape architecture design is to serve the visual requirements. In the discussion of the theory and method of urban landscape architecture planning, he also focuses on the visual research.

\section{The Mode of Implementation of Plant Therapy}

The urban human settlements can be divided into the near residential environment, the community environment and the urban environment from micro to mesa to macro. The near residential environment is divided into two parts: residential and neighborhood environment. The community environment is the main environment for the residents' social activities, and the urban environment is equivalent to the whole urban system environment. In close proximity to the residential environment, plant therapy, mainly residential green spaces, Roof garden and home gardening therapy garden. In community settings, plant treatments are mainly community parks and community intensive green spaces, which is as Figure.2.

The different types of city garden plant therapy can be divided with the city open green space, green space, green space attached to suburban. Medical institutions are usually built to carry out the activities of garden plant therapy treatment, as the auxiliary and supplement of the traditional therapy [7-8].

The medical botanical garden should meet the medical requirements. With diversified attraction and strong stop feeling place, interaction with the natural mind brought through the place design experience for everyone to participate and experience, the chance of cure, is the ultimate goal of building design and treatment plant garden. The purpose of constructing a horticultural activity area is to achieve physical rehabilitation by participating in certain suitable garden or gardening 
activities to strengthen people's physique.

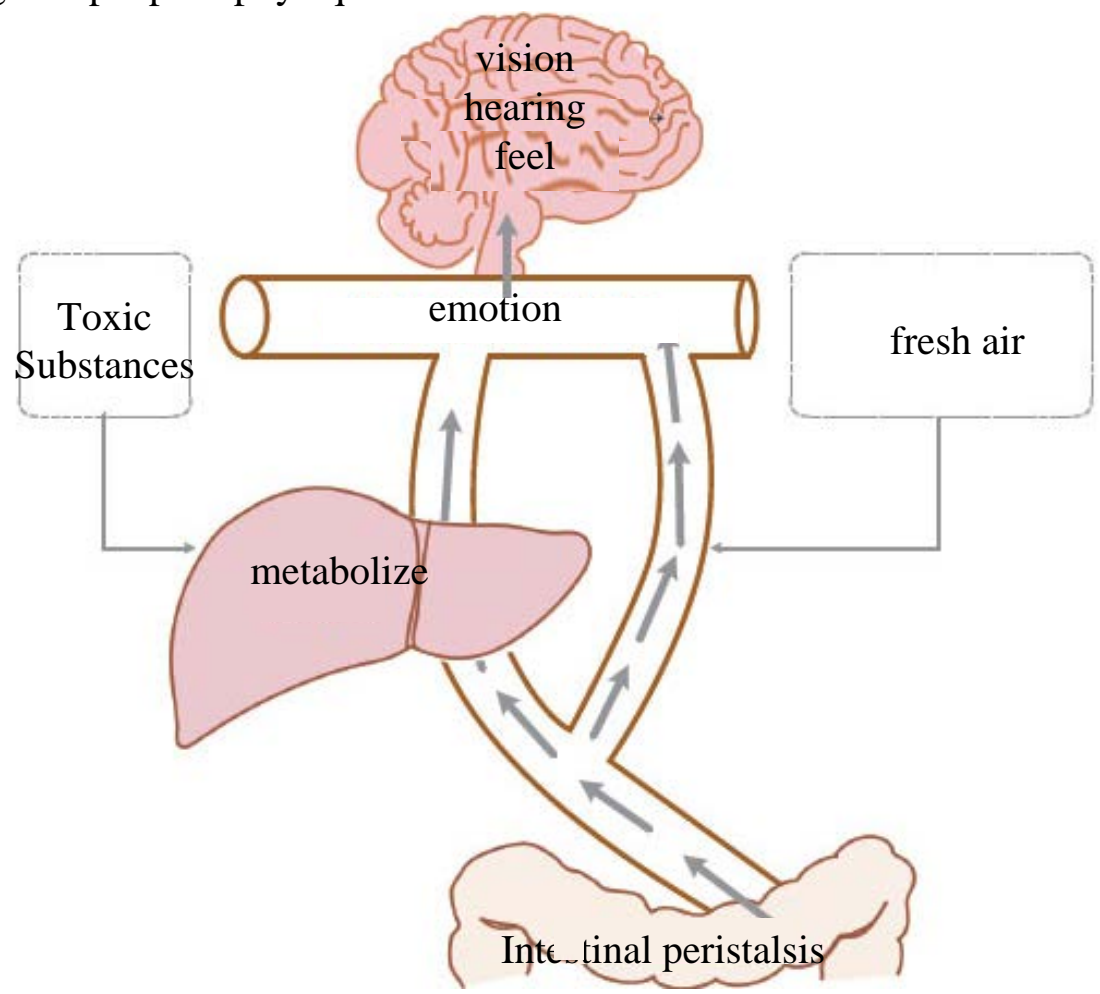

Fig.2. The mechanism of action of plant therapy

Horticultural therapy usually uses plant cultivation and gardening operations to adjust patients from social, educational, psychological, and physical aspects. Work is one of the most important horticultural therapy, such as weeding, through activities increase the participant vitality, establish confidence, cultivate patience, improve attention, activities and stretching and strengthening exercises function, feel the rhythm of life. Choose the beautiful environment and gardening activities, activity design for patients with mental and physical condition, carefully selected can improve the patient's perception and social cooperation ability, easy cultivation of plants, so that they benefit from. The construction of botanical garden highlights the close relationship between landscape plants and human beings and human health, and will enhance people's awareness of environment and ecology.

\section{Conclusion}

Plant therapy is still in its early stage of development in China, and it is imperative to carry out research, education and professional training. The establishment of horticultural therapy certification system, personnel training for professional landscape, combined with our current implementation of the pilot plant therapy and popularization activities, to research and education as the support and technical reserves, to establish practice physiotherapy mass basis, to better promote the development of our plant therapy. Landscape architecture is a broad and profound field, and it will be exposed to more and more unknown fields, covering a wide range of disciplines, the same is true of plant therapy, each in-depth point, we need more detailed and in-depth research and work.

\section{Acknowledgement}

In this paper, the research was sponsored by the Nature Science Foundation of Henan Province (Project No. 201112400450401) and Youth Fund Project of Luoyang Institute of Science and Technology (Project No. 2010QZ16). 


\section{References}

[1] Ms. Nancy Gerlach-Spriggs, Richard Kaufman, Sam Bass Warner Jr. Restorative Gardens: The Healing Landscape[J]. Yale University Press, 2014,9

[2] J S Leslie. Spiritual Garden Design: How to Create a Sacred Sanctuary in Your Own Backyard[J]. Time Life Education,2016,1

[3] J Stoneham, P R Thoday. Landscape design for elderly \& disabled people[J].West Sussex, UK: Packard Publishing Limited, 2014.

[4] A Watts. Every Nursery Needs a Garden: A Step-by-step Guide to Creating and Using a Garden with Young Children[J]. Routledge,2016.

[5] Banry Benefits. Horticultural therapy in adjuvant treatment of chronic schizophrenia patients to observe [J].the effect of nursing, 2015,16 (9): 518-520

[6] Li Ming .analysis of practical nursing bandy benefit rehabilitation effect of gardening therapy on chronic schizophrenia[J] the effect of nursing,2016,18 (2): 50-51

[7] Mei Ling, Li Shuhua. Preliminary study on the influence of horticultural operation on the health of the elderly. the effect of nursing[J]. Chinese garden, 2014,22 (6): 4649

[8] Yang Xiaoming, Hi Guo Xing. Horticultural therapy and its application in garden .the effect of nursing[J]. Journal of Southwest Forestry University, 2017,22 (5): 43-45 